\title{
Changes in the glycosylation pattern of circulating gonadotropins after acute administration of gonadotropin- releasing hormone in patients with anorexia nervosa
}

\author{
Silvia Savastano, Antonio P Tommaselli, Rossella Valentino ${ }^{1}$, Antonio Luciano, Marianna Gigante, \\ Giacomino Randazzo ${ }^{2}$, Franco Contaldo ${ }^{3}$, Luca Scalfi ${ }^{2}$ and Gaetano Lombardi \\ Department of Molecular and Clinical Endocrinology and Oncology, ${ }^{1}$ Experimental Endocrinology and Oncology Center, CNR, ${ }^{2}$ Department of Food \\ Science, ${ }^{3}$ Department of Experimental and Clinical Medicine, University Federico II, Naples, Italy \\ (Correspondence should be addressed to S Savastano, Chair of Endocrinology, Department of Molecular and Clinical Endocrinology and Oncology, \\ University Federico II Medical School, via S Pansini 5, 80131 - Naples, Italy)
}

\begin{abstract}
To study the involvement of gonadotropin-releasing hormone (GnRH) in glycosylation of circulating gonadotropin isoforms in anorexia nervosa (AN), 14 amenorrhoic patients with AN, 14 age-matched volunteers in early follicular phase, and five normal-weight re-fed patients with AN were investigated under baseline conditions and after acute administration of GnRH. Plasma gonadotropins were assayed using IRMA before and after concanavalin A affinity chromatography. Baseline plasma gonadotropin levels were lower for both AN and re-fed AN patients than in controls $(P<0.005)$. The increase in FSH and $\mathrm{LH}$ after GnRH administration was lower than in controls for AN $(P<0.005)$ and re-fed AN $(P<0.005$ and $P<0.05$ respectively $)$ patients. Percentages of total gonadotropin not bound to concanavalin A (complex carbohydrate chains) under baseline conditions were higher in patients with AN than in controls $(P<0.005)$ but decreased after $\mathrm{GnRH}$ administration $(P<0.001)$. In re-fed AN patients, the percentage of unbound FSH was higher than in controls $(P<0.05)$, and decreased after GnRH administration $(P<0.001)$, whereas the percentages of unbound LH were not significantly different from controls either before or after GnRH administration. These data suggest that: (a) the acute administration of $\mathrm{GnRH}$ induces quantitative and qualitative changes in circulating gonadotropin isoforms in both normal controls and AN patients; (b) during recovery the LH response in re-fed AN patients is associated with a glycosylation pattern that is the same as that for controls.
\end{abstract}

European Journal of Endocrinology 138 76-81

\section{Introduction}

Anorexia nervosa (AN) is a complex psychiatric disorder, with increasing incidence especially among adolescent and young women, associated with multiple disturbances in central monoaminergic systems and endocrine abnormalities (1). Dysfunctions in the hypothalamus-pituitary-gonadal axis and amenorrhea are common features (2). Although a clear relationship exists between menstrual dysfunction, weight loss and malnutrition, amenorrhea can predate weight loss and may persist despite weight gain $(2,3)$. An abnormality in the central regulation of the gonadotropin-releasing hormone $(\mathrm{GnRH})$ pulse-generation system has been described in both undernourished animal models (4-6) and humans with AN, with a reduced gonadotropin pulsatility and an age-inappropriate gonadotropin secretion pattern (3, 7-10). Pulsatile GnRH therapy in AN patients has been reported to induce the quantitative restoration of both episodic luteinizing hormone (LH) secretion and pituitary LH responsiveness to $\mathrm{GnRH}$ (11). However, the central mechanism underlying dietinduced hypogonadism remains unexplained and persists after the return to a normal diet $(1-3,6,12)$.

The microheterogeneity of gonadotropin isoforms is well known in both physiologic and pathologic conditions (13-18). Similarly to thyrotropin-releasing hormone (19-23), a direct effect of GnRH on gonadotropin $\mathrm{N}$-linked carbohydrate branching has been postulated to occur (17-18). Qualitative changes in both circulating follicle-stimulating hormone (FSH) and LH occur in amenorrhoic AN patients, with evidence of circulating gonadotropin isoforms that are less sialylated (24). Although the effects of exogenous GnRH administration on gonadotropin isoform distribution pattern have been evaluated in animal models $(6,12)$ and humans under different conditions (25-28), no studies have been performed on patients with AN to evaluate whether the acute $\mathrm{GnRH}$ administration influences circulating gonadotropin glycosylation. 
The pattern of elution of plasma gonadotropins from concanavalin A (Con A) was therefore investigated in 14 amenorrhoic patients with AN and five normalweight re-fed AN patients before and after acute administration of exogenous GnRH in comparison with 14 age-matched normally cycling women.

\section{Materials and methods}

\section{Subjects and study procedure}

Fourteen hospitalized females, aged 16-27 years, with AN and secondary amenorrhea lasting at least 6 months, and 14 age-matched volunteers of normal weight and with regular menstrual periods, some of whom had already enrolled in our previous study (24), were investigated. The AN patients weighed less than $70 \%$ of ideal body weight, with body mass index $<17$ (normal values (n.v.) $20-25 \mathrm{~kg} / \mathrm{m}^{2}$ ). Ideal body weights were determined from the Metropolitan Life Insurance Co. tables of New York 1983 (29). Five re-fed AN patients, aged 19-31 years with body mass index $>20$, were included in the study; they had all attained normal eating behavior and a weight greater than $85 \%$ of ideal for at least 6 months, and two had resumed regular menstrual periods (three and five menses). All the patients were recruited from the Clinical Nutrition Unit of Federico II University; informed consent had been given in accordance with the Helsinki Declaration. Diagnoses were based on the Diagnostic and Statistical Manual of Mental Disorders (DSM IV) criteria (30). No patient or control was taking any medication known to affect ovary function or had received prior estrogen therapy. Re-fed AN patients and normal controls were evaluated in the precocious follicular phase (4-6 days after the onset of uterine bleeding).

$\mathrm{GnRH}$ tests were performed between 0800 and $1000 \mathrm{~h}$ after an overnight fast. Blood samples were obtained immediately before and 15, 45, 60 and $90 \mathrm{~min}$ after the i.v. injection of $100 \mu \mathrm{g} \mathrm{GnRH}$ (Relisorm L100; Serono, Roma, Italy), via an indwelling antecubital venous catheter. The samples were centrifuged and stored at $-80{ }^{\circ} \mathrm{C}$ until assayed.

\section{RIA}

Gonadotropins in both plasma and Con A-affinity column fractions were measured in duplicate using an ultrasensitive IRMA (FSH IRMA CT and LH IRMA CT; Radim, Pomezia, Italy; n.v. 2.5-13 and 1.4-13 IU/l respectively) employing a combination of two monoclonal antibodies: a tube-immobilized $\beta$-specific antibody and a labeled one specific for the intact FSH and LH dimers. The sensitivity of the IRMA (level at mean $B_{0} \pm 2.5$ S.D.) was $0.1 \mathrm{IU} / \mathrm{l}$ for both $\mathrm{FSH}$ and LH. The intra-assay coefficients of variation for low and medium values were for FSH 5.1 and $2.7 \%$ respectively and for LH 2.8 and $1.5 \%$ respectively. Plasma levels of $17 \beta$ - estradiol were assayed three times under basal conditions (4-6th day) by RIA using commercial kits (CIS; Tronzano Vercellese, Italy; n.v. 70-220 nmol/l).

\section{Con A affinity chromatography}

As previously reported (24), $1 \mathrm{ml}$ aliquots of unextracted serum were added to $3 \mathrm{ml} 50 \%(\mathrm{v} / \mathrm{v})$ agarosebound Con A (Pharmacia Fine Chemicals, Milan, Italy) in PBS $(0.01 \mathrm{~mol} / \mathrm{l}$ phosphate and $0.15 \mathrm{~mol} / \mathrm{l} \mathrm{NaCl}$, $\mathrm{pH}$ 7.4). They were subsequently placed on $10 \mathrm{ml}$ columns, incubated at room temperature and shaken for $1 \mathrm{~h}$. The FSH and LH fractions that did not bind to Con A (UB) were obtained after centrifugation for $30 \mathrm{~min}$ at $1000 \mathrm{~g}$ at $4^{\circ} \mathrm{C}$. The Con A-bound FSH and LH fractions were obtained using the same buffer containing $300 \mathrm{mmol} \alpha$-methyl mannopyranoside, with a total recovery of $85-98 \%$. The column fractions were stored at $-20{ }^{\circ} \mathrm{C}$ until immunoassayed. Percentages of unbound FSH and LH (\% FSH-UB and \% LH-UB) were calculated as the ratio of FSH-UB and LH-UB to total FSH and LH concentrations.

\section{Statistical tests}

Plasma gonadotropin concentrations were log-transformed before statistical analysis to correct for the heterogeneity of variance. Statistical differences between baseline and post-treatment values were assessed by ANOVA between groups, followed by Newman-Keuls' test and Student's unpaired $t$-test. Differences at $P<0.05$ were considered statistically significant. Significant relationships between variables were analyzed using Pearson product-moment correlations.

\section{Results}

Plasma FSH and LH levels of AN patients $(n=14)$, re-fed AN patients $(n=5)$ and controls $(n=14)$ during baseline and GnRH-stimulated conditions are reported in Table 1. Maximum values for FSH and LH were obtained after $45 \mathrm{~min}(P<0.001)$. A significant difference is observed up to $90 \mathrm{~min}$ after $\mathrm{GnRH}$ administration $(P<0 \cdot 05)$, except for LH values for AN patients. For FSH and LH, mean values were significantly lower for both AN patients and re-fed AN patients than normal controls under baseline conditions $(P<0.005)$. After acute $\mathrm{GnRH}$ challenge, the maximum values for $\mathrm{FSH}$ and LH were significantly lower for AN patients than for controls $(P<0.005)$. The maximun FSH and LH values were also significantly lower for re-fed $\mathrm{AN}$ patients than for controls, although to a different significance $(P<0.005$ and $P<0.05$ respectively).

The mean values of \% FSH-UB and \% LH-UB before and after GnRH stimulation are reported in Table 2. The minimum values during the test, expressed as mean \pm S.D., were obtained after $45 \mathrm{~min} \quad(P<0.001$ except for \% LH-UB for normal controls and re-fed AN 
Table 1 Plasma FSH and LH concentrations after an acute challenge with $100 \mu \mathrm{g} \mathrm{GnRH}$.

\begin{tabular}{|c|c|c|c|c|c|c|}
\hline \multirow{2}{*}{$\begin{array}{l}\text { Time after } \\
\text { GnRH (min) }\end{array}$} & \multicolumn{3}{|c|}{ Plasma FSH (IU/I) } & \multicolumn{3}{|c|}{ Plasma LH (IU/I) } \\
\hline & NC & AN & Re-fed AN & NC & AN & Re-fed AN \\
\hline 0 & $\begin{array}{c}8.7 \\
(6.5,12.0)\end{array}$ & $\begin{array}{c}2.0^{\mathrm{b}} \\
(2.0,5.8)\end{array}$ & $\begin{array}{c}4.1^{\mathrm{b}} \\
(1.9,11.6)\end{array}$ & $\begin{array}{c}7.5 \\
(5.6,10.7)\end{array}$ & $\begin{array}{c}0.5^{\mathrm{b}} \\
(0.9,2.3)\end{array}$ & $\begin{array}{c}3.2^{\mathrm{b}} \\
(1.4,14.8)\end{array}$ \\
\hline 15 & $\begin{array}{c}12.2 \\
(7.6,20.9)\end{array}$ & $\begin{array}{c}4.0 \\
(2.9,12.5)\end{array}$ & $\begin{array}{c}7.1 \\
(2.6,23.4)\end{array}$ & $\begin{array}{c}9.8 \\
(7.4,13.4)\end{array}$ & $\begin{array}{l}2.7 \\
(2.3,10.8)\end{array}$ & $\begin{array}{c}6.3 \\
(2.1,25.2)\end{array}$ \\
\hline 45 & $\begin{array}{c}17.7^{\star a} \\
(118241)\end{array}$ & $9.0^{* a, b}$ & $12.7^{\star a, b}$ & $\begin{array}{c}17.5^{\star a} \\
(11767)\end{array}$ & $5.0^{\star a, b}$ & $\begin{array}{l}13.0^{\star a, c} \\
(2938.11\end{array}$ \\
\hline 90 & $\begin{array}{c}14.8,8^{\mathrm{d}} \\
(9.2,24.3)\end{array}$ & $\begin{array}{c}(4.9,20.4) \\
8.5^{d} \\
(5.0,17.1)\end{array}$ & $\begin{array}{c}(5.6,29.3) \\
9.5^{\mathrm{d}} \\
(6.9,13.3)\end{array}$ & $\begin{array}{c}(11.7,26.7) \\
15.2^{\mathrm{d}} \\
(8.1,30.0)\end{array}$ & $\begin{array}{c}(3.1,33.7) \\
4.3 \\
(2.7,28.8)\end{array}$ & $\begin{array}{c}(2.9,38.1) \\
9.4^{d} \\
(3.1,32.5)\end{array}$ \\
\hline
\end{tabular}

Values are geometric means and their $95 \%$ confidence limits for the concentrations.

NC, normal controls $(n=14)$; AN, patients with AN $(n=14)$; Re-fed AN, normal-weight re-fed AN patients $(n=5)$.

* Maximum value during the test.

${ }^{\mathrm{a}} P<0.001$ vs baseline; ${ }^{\mathrm{b}} P<0.005$ vs NC; ${ }^{\mathrm{c}} P<0.05$ vs NC; ${ }^{\mathrm{d}} P<0.05$ vs baseline.

patients). A significant difference is observed up to 90 min after $\mathrm{GnRH}$ administration for both \% FSH-UB and \% LH-UB for AN patients, and for \% FSH-UB only for re-fed AN patients $(P<0.001)$. Under baseline conditions, the \% FSH-UB values were significantly higher for both $\mathrm{AN}$ and re-fed AN patients than controls $(P<0.005)$. The \% LH-UB was also significantly higher in AN patients than controls $(P<0.005)$, while the values for re-fed $A N$ patients did not significantly differ from controls. After acute GnRH challenge, the minimum values for \% LH-UB were significantly higher for AN patients than for controls at 45-90 min $(P<0.05)$. No difference was found for \% FSH-UB values between the three groups, and for \% LH-UB values between re-fed AN patients and controls after $90 \mathrm{~min}$. Therefore for $\%$ FSH-UB the significant differences between groups under baseline conditions were no longer evident after the acute GnRH challenge, while for \% LH-UB a difference was still present at 45 and 90 min for AN patients, although with a lower significance than under baseline conditions $(P<0.05)$.

Baseline plasma $17 \beta$-estradiol levels were significantly lower in AN patients than in re-fed AN patients and normal controls $(23.1 \pm 4.9$ vs $80.9 \pm 21.5$ and $89.5 \pm 16.3 \mathrm{nmol} / \mathrm{l}$ respectively).
No significant correlation was observed between either \% FSH-UB or \% LH-UB and body mass index in AN patients, or between weight, weight gain, and duration of refeeding in re-fed AN patients. A weak negative correlation was found in normal controls between maximum FSH values and minimum \% FSH-UB values at $45 \min (r=-0.6)$.

\section{Discussion}

We previously found a significant increase in the percentage of FSH and LH molecules not retained on Con A (complex-type asparagine-linked oligosaccharides) in a group of amenorrhoic AN patients than in eumenorrhoic normal-weight controls, and we related this alteration to a decrease in gonadotropin bioactivity (24). In the present experiment, we have shown that, in spite of low plasma concentrations of stimulated gonadotropin, the glycosylation pattern of gonadotropins in AN patients is modified immediately after an acute GnRH challenge. In particular, in accord with previous reports $(26,27,31)$, in normal controls a single acute GnRH dose significantly decreases \% FSH-UB $45 \mathrm{~min}$ after GnRH injection, without any further decrease in the naturally occurring secretion of

Table 2 Percentage of Unbound FSH and LH fractions (UB) after an acute challenge with $100 \mu \mathrm{g}$ GnRH. Values are means \pm SD.

\begin{tabular}{|c|c|c|c|c|c|c|}
\hline \multirow{2}{*}{$\begin{array}{l}\text { Time after } \\
\text { GnRH (min) }\end{array}$} & \multicolumn{3}{|c|}{ Plasma FSH (IU/I) } & \multicolumn{3}{|c|}{ Plasma LH (IU/I) } \\
\hline & NC & AN & Re-fed AN & NC & AN & Re-fed AN \\
\hline 0 & $80.5 \pm 9.3$ & $96.7 \pm 7.7^{\mathrm{b}}$ & $95.3 \pm 2.1^{b}$ & $15.2 \pm 7.0$ & $74.4 \pm 16.9^{b}$ & $18.1 \pm 5.4$ \\
\hline 15 & $71.7 \pm 9.7$ & $70.5 \pm 17.2$ & $75.6 \pm 8.3$ & $14.1 \pm 5.5$ & $51.6 \pm 29.3$ & $16.3 \pm 2.7$ \\
\hline 45 & $65.2 \pm 11.7^{\star a}$ & $57.0 \pm 11.4^{\star a}$ & $65.3 \pm 7.4^{\star a}$ & $10.5 \pm 3.5^{\star}$ & $21.5 \pm 15.9^{\star a, c}$ & $12.1 \pm 0.7^{*}$ \\
\hline 90 & $74.6 \pm 9.2$ & $64.1 \pm 15.0^{\mathrm{a}}$ & $68.2 \pm 6.2^{\mathrm{a}}$ & $11.4 \pm 3.9$ & $21.5 \pm 14.1^{\mathrm{a}, \mathrm{c}}$ & $13.2 \pm 1.5$ \\
\hline
\end{tabular}

NC, normal controls $(n=14)$; AN, patients with AN $(n=14)$; Re-fed AN, normal-weight re-fed AN patients $(n=5)$

${ }^{*}$ Minimum value during the test.

${ }^{\text {a }} P<0.001$ vs baseline; ${ }^{\text {b }} P<0.005$ vs NC; ${ }^{\mathrm{c}} P<0.05$ vs NC. 
baseline unbound LH isoforms. Conversely, in AN patients, a single acute GnRH dose significantly reduces the abnormally high percentage of unbound FSH and LH 45 min after GnRH injection, so that for FSH-UB the significant baseline differences between $A N$ patients and controls are no longer evident, whereas for LH-UB they are still present, although to a lower significance than under baseline conditions. In other words, the intrapituitary gonadotropin pools of patients with AN contain higher amounts of mannose-rich less-sialylated molecules after acute $\mathrm{GnRH}$ administration than before, and these higher concentrations are the same as baseline concentrations in control subjects in the follicular phase, as previously reported to occur in thyrotropin secretion after thyrotropin-releasing hormone administration (19-21, 32). In AN, changes in the percentage of unbound FSH and $\mathrm{LH}$ are still evident $90 \mathrm{~min}$ after GnRH administration, whereas in normal controls the percentage of unbound FSH returned to baseline values. This may be related to a relative impairment of the unstimulated pituitary to process the gonadotropin molecules to more mature isoforms, as also described for thyrotropin $(19,20)$. Conversely, in normal controls, also taking into account the selective survival of serum isoforms, the secretion of all available isoforms follows the initial preferential release of bound isoforms $90 \mathrm{~min}$ after GnRH. As naturally occurring FSH contains more complex-type oligosaccharide chains than LH (31), the effect of GnRH appears to be more striking on LH than on FSH, particularly for AN patients.

Similarly to AN patients, re-fed AN patients exhibit higher \% FSH-UB values than normal controls, with a significant decrease after GnRH administration; however, neither baseline nor stimulated \% LH-UB values were significantly different from normal controls. This suggests that, in normal-weight re-fed AN patients, the increase in basal plasma levels of estrogen is related to the secretion of $\mathrm{LH}$ isoforms that are not different from those of control subjects in the follicular phase, probably because of restoration of the endogenous GnRH pulse frequency. In this context, the changes in baseline and stimulated LH glycoisoforms in re-fed AN patients may provide a possible additional marker for the prediction of the reversal of endocrine abnormalities.

The microheterogeneity of pituitary and circulating gonadotropin isoforms appears to be related to the endocrine milieu (18). In particular, $\mathrm{GnRH}(25-27,33)$ and estrogens $(12,34-39)$ have been proposed to be physiologic modulators of gonadotropin polymorphism. Although a direct estrogen effect on the glycosyltransferases in the pituitary has also been postulated (40), the relative roles of increased GnRH pulse frequency and rising sex hormone concentration have not been clarified (26). Previous data obtained in animal models suggest that nutritional factors and percentage of body fat are also relevant to the failure of the GnRH neurosecretory mechanism, with depression of gonadotropin secretion independently of ovarian presence $(4,6)$. No studies in humans have as yet provided clear information on the relevance of nutritional status to the central mechanism underlying diet-induced hypogonadism, in particular in $\mathrm{AN}(2,8,9,33)$. In this context, the study of chronic undernourished AN patients, with low plasma levels of endogenous estrogen and without estrogen replacement therapy, represents a useful approach for evaluating the effects of endogenous alteration of pulsatile GnRH secretion on gonadotropin isoform secretion. The present paper is the first to show in humans a relationship between $\mathrm{GnRH}$, amenorrhea, nutrition and body weight, although their exact roles remain to be defined $(2,3)$. Previous experiments have been performed on prepubertal animal models before the development of a mature reproductive system dependent on exogenous nutritional manipulations. In contrast, our studies were performed on reproductively regressed adults, with fully established reproductive neuroendocrine system and endogenous eating behavior alterations. In spite of the metabolic and endocrine differences between animal and human models, our data confirm the effect of acute GnRH administration on the glycosylation pattern of gonadotropins in $\mathrm{AN}$ patients. In re-fed $\mathrm{AN}$ patients, the effect of $\mathrm{GnRH}$ may be related to weight gain and increase in estrogens. In AN, however, we cannot infer that the GnRH effect is mediated through estrogenic influences, as changes in gonadotropin isoforms are also observed in the presence of low estrogen concentrations without interference from estrogen replacement therapy. Finally, the involvement of ovarian factors other than sex steroids, such as inhibin, activin and follistatin, cannot be excluded from the present study.

Although further evidence obtained with a larger group of patients is required to confirm this hypothesis, our data suggest that, as far as patients with AN are concerned, nutritional state, body fat increase, $\mathrm{GnRH}$ and estrogen concentrations are presumably only cofactors in the pathogenesis of amenorrhea. This hypothesis is in line with neuroendocrine dysregulation of gonadotropin secretion in $\mathrm{AN}$ being part of the overall alteration of the monoaminergic neurotransmission underlying the eating behaviour disturbances. In conclusion, AN patients provide a suitable and original model for evaluating the effects in vivo of $\mathrm{GnRH}$ administration upon gonadotropin glycosylation pattern. In these patients, the abnormalities in glycosylation of gonadotropin isoforms are reversed by acute $\mathrm{GnRH}$ administration. The contribution of chronic energy deprivation during refeeding needs to be further investigated.

\section{Acknowledgements}

The authors are very grateful to the 'Gruppo di Studio in Endocrinologia' (G.S.E., Naples, Italy) for financial support. 


\section{References}

1 Garner DM. Pathogenesis of anorexia nervosa. Lancet 1993341 1631-1635.

2 Foster DW. Eating disorders: obesity and anorexia nervosa. In Williams Textbook of Endocrinology, edn VII, pp 1081-1107. Eds JD Wilson \& DW Foster. Philadelphia: WB Saunders Co., 1985.

3 Newman MM, Katherine A \& Halmi MD. The endocrinology of anorexia nervosa and bulimia nervosa. Endocrinology and Metabolism Clinics of North America 198817 195-212.

4 Foster DL, Ebling FJP, Micka AF, Vannerson LA, Bucholtz DC, Wood RI et al. Metabolic interfaces between growth and reproduction. I. Nutritional modulation of gonadotropin, prolactin, and growth hormone secretion in the growth-limited female lamb. Endocrinology 1988125 342-350.

5 Padmanabhan W, Ebling FJP, Sonstein J, Fenner DE, Kelch RP, Foster DL et al. Bioactive follicle-stimulating hormone release in nutritionally growth retarded ovariectomized lambs: regulation by nutritional repletion. Endocrinology 1989125 2517-2526.

6 Ebling FJP, Wood RI, Karsch FJ, Vannerson LA, Suttie JM, Bucholtz DC et al. Metabolic interfaces between growth and reproduction. III. Central mechanisms controlling pulsatile luteinizing hormone secretion in the nutritionally growth-limited female lamb. Endocrinology $19901262719-2727$.

7 Boyar RM, Katz J, Finkelstein JW, Kapen S, Weiner H, Weitzam ED et al. Anorexia nervosa: immaturity of the 24-hour luteinizing hormone secretory pattern. New England Journal of Medicine 1974 $291861-865$.

8 Pirke KM, Spyra B, Warnhoff M, Kuderling I, Dorsch G \& Gramsch C. Effect of starvation on central neurotransmitter systems and on endocrine regulation. In The Psychobiology of Anorexia Nervosa, pp 46-57. Eds KM Pirke \& D Ploog. New York: Springer-Verlag, 1984.

9 Russel J \& Beumont PJV. The endocrinology of anorexia nervosa. In The Handbook of Eating Disorders, Part I: Anorexia and Bulimia Nervosa, pp 201-234. Eds PJV Beumont, GD Burrows \& RC Casper. Amsterdam: Elsevier, 1987.

10 Garcia-Rubi E, Vazquez-Alemàn D, Mendez JP, Salinas JL, GarzaFlores J, Ponce-de-Leòn S et al. The effects of opioid blockade and GnRH administration upon luteinizing hormone secretion in patients with anorexia nervosa during the stages of weight loss and weight recovery. Clinical Endocrinology $199237520-528$.

11 Marshall JC \& Kelch RP. Low dose pulsatile gonadotropin releasing hormone in anorexia nervosa. A model of human pubertal development. Journal of Clinical Endocrinology and Metabolism $197949712-719$

12 Hassing JM, Kletter GB, I'Anson H, Wood RI, Beitins IZ, Foster DL et al. Pulsatile administration of gonadotropin-releasing hormone does not alter the follicle-stimulating hormone (FSH) isoform distribution pattern of pituitary or circulating FSH in nutritionally growth-restricted ovariectomized lambs. Endocrinology 1992132 1527-1536.

13 Wide L. Median charge and charge heterogeneity of human pituitary FSH, LH and TSH. Acta Endocrinologica 1985109 181-185.

14 Ulloa-Aguirre A, Espinoza R, Damian-Matzumura P \& Chappel SC. Immunological and biological potencies of the different molecular species of gonadotropins. Human Reproduction 19883 491-501.

15 Gharib SH, Wierman ME, Shupnik MA \& Chin WW. Molecular biology of the pituitary gonadotropins. Endocrine Reviews 199011 177-198.

16 Papandreou MJ, Darbon H \& Ronin C. Polymorphisme biologique et doamines fonctionelles des hormones glycoproteiques hypophysaires. Annals of Endocrinology 199152 (Suppl 4) 254-268.

17 Wide L. Les facteurs intrinsèques et extrinsèques qui influencent la stimulation des gonades et la rèceptivè des tissus gènitaux fèmminins. Formes circulantes des gonadotrophines et leur variabilite. Les gonadotrophines chez l'homme. Contraception, Fertilité, Sexualité 19924 455-462.
18 Ulloa-Aguirre A, Midgley AR, Beitins IZ \& Padmanabhan V. Follicle-stimulating isohormones: characterization and physiological relevance. Endocrine Reviews 199516 765-787.

19 Taylor T \& Weintraub BD. Altered thyrotropin (TSH) carbohydrate structure in hypothalamic hypothyroidism created by paraventricular nuclear lesion are corrected by in vitro TSHreleasing hormone administration. Endocrinology 1989125 2198-2203.

20 Magner JA. Thyroid-stimulating hormone: biosynthesis, cell bology, and bioactivity. Endocrine Reviews 199011 (Suppl 2) 354-385.

21 Magner JA, Kane J \& Chou ET. Intravenous thyrotropin (TSH)releasing hormone releases human TSH that is structurally different from basal TSH. Journal of Clinical Endocrinology and Metabolism 199274 1306-1311.

22 Miura Y, Perkel VS, Papenberg KA, Johnson MJ \& Magner JA. Concanavalin-A, lentil, and ricin lectin affinity binding characteristics of human thyrotropin: differences in the sialylation of thyrotropin in sera of euthyroid, primary and central hypothyroid patients. Journal of Clinical Endocrinology and Metabolism 198969 (Suppl 5) 985-995.

23 Papandreou MJ, Persani L, Asteria C, Ronin C \& Beck-Peccoz P. Variable carbohydrate structures of circulating thyrotropin as studied by lectin affinity chromatography in different clinical conditions. Journal of Clinical Endocrinology and Metabolism 1993 77 (Suppl 2) 393-398.

24 Tommaselli AP, Valentino R, Savastano S, Randazzo G, Scalfi L, Contaldo $\mathrm{F}$ et al. Altered glycosylation of pituitary gonadotropins in anorexia nervosa: an alternative explanation for amenorrhea. European Journal of Endocrinology 1995132 450-455.

25 Wide L \& Albertsson-Wikland K. Change in electrophoretic mobility of human follicle-stimulating hormone in serum after administration of gonadotropin-releasing hormone. Journal of Clinical Endocrinology and Metabolism 199070 271-276.

26 Zambrano E, Olivares A, Mendez JP, Guerrero l, Diaz-Cueto L, Veldhuis JD et al. Dynamics of basal and gonadotropin-releasing hormone-releasable serum follicle-stimulating hormone charge isoform distribution throughout the human menstrual cycle. Journal of Clinical Endocrinology and Metabolism $1995801647-$ 1656.

27 Phillips DJ \& Wide L. Serum gonadotropin isoforms become more basic after an exogenous challenge of gonadotropin-releasing hormone in children undergoing pubertal development. Journal of Clinical Endocrinology and Metabolism 199479 814-819.

28 Wide L, Albertsson-Wikland K \& Phillips DJ. More basic isoforms of serum gonadotropins during gonadotropin-releasing hormone agonist therapy in pubertal children. Journal of Clinical Endocrinology and Metabolism 199681 216-221.

29 Metropolitan Life Insurance Company. Metropolitan height and weight tables. Statistical Bulletin 198364 2-9.

30 American Psychiatric Association. Diagnostic and Statistical Manual of Mental Disorders, edn 4. (DSM IV). Washington DC: APA Press, 1994.

31 Papandreou MJ, Asteria C, Pettersson K, Ronin C \& Beck-Peccoz P. Concanavalin A affinity chromatography of human serum gonadotropins: evidence for changes of carbohydrate structure in different clinical conditions. Journal of Clinical Endocrinology and Metabolism 199376 1008-1013.

32 Beck-Peccoz P, Amr S, Menezes-Ferreira MM, Faglia G \& Weintraub BD. 1985 Decreased receptor-binding of biologically inactive thyrotropin in central hypothyroidism: effect of treatment with thyrotropin-releasing hormone. New England Journal of Medicine 1985312 1085-1090.

33 Binsbergen CJM, Coeling Bennik HJT, Odink J, Haspel AA \& Koppeschaar HPF. A comparative longitudinal study on endocrine changes related to ovarian function in patients with anorexia nervosa. Journal of Clinical Endocrinology and Metabolism 199071 705-711.

34 Padmanabhan V, Miceher CD, Borondy M, I'Anson H, Wood RI, Landefeld TD et al. Circulating bioactive follicle-stimulating 
hormone and less acidic follicle-stimulating hormone isoforms increase during experimental induction of puberty in the female lamb. Endocrinology 1992131 1131-1138.

35 Flack MR, Bennet AP, Froehlich J Anastasi JN \& Nisula B. Increased biological activity due to basic isoforms in recombinant human follicle-stimulating hormone produced in a human cel line. Journal of Clinical Endocrinology and Metabolism 199479 756-760.

36 Padmanabhan V, Lang LL, Sonstein J, Kelch RP \& Beitins IZ Modulation of serum follicle-stimulating hormone bioactivity and isoform distribution by estrogenic steroids in normal women and in gonadal dysgenesis. Journal of Endocrinology and Metabolism $198867465-473$

37 Wide L \& Naessén T. 17 $\beta$-Oestradiol counteracts the formation of the more acidic isoforms of follicle-stimulating hormone and luteinizing hormone after menopause. Clinical Endocrinology $199440783-789$
38 Wide L \& Naessen T. Effect of chronic oral administration of $17 \beta$ oestradiol and norethisterone on the isoforms of serum gonadotrophins in post-menopausal women. Clinical Endocrinology 1995 42 59-64.

39 Wide L. Median charge and charge heterogeneity of human pituitary FSH, LH and TSH. II. Relationship to sex and age. Acta Endocrinologica 1985109 190-197.

40 Dharmesh SM \& Baenziger JU. Estrogen modulates expression of the glycosyltransferases that synthesize sulphated oligosaccharides on lutropin. Proceedings of the National Academy of Sciences of the USA $19939011127-11131$.

Received 23 April 1997

Accepted 26 August 1997 